\title{
Replenishment Decision and Coordination in the Agricultural Supply Chain Under Supply Disruption
}

\author{
Bei Xia \\ School of Agriculture, Yangzhou University, Yangzhou, Jiang Su, 225002, China \\ angelkittybei@163.com
}

Keywords: Supply disruption; Coordination; Replenishment decision; Agricultural supply chain.

\begin{abstract}
This paper mainly focuses on the supplier and retailer how to deal with the supply disruption when it has happened. To end this, we establish a model which consists of a retailer, a supplier and a spot market. To get benchmark, we first investigate optimal decisions under the normal situation. Subsequently, we study the situation of supply disruption and get optimal decision of replenishment under two scenarios: centralized supply chain and decentralized supply chain. Comparing these results, we then find that the replenishment decision under decentralized supply chain is not consistent with that under centralized supply chain in most cases. It implies that supplier makes replenishment decision just according to her own situation which may undermine the supply chain's profits. To solve this issue, we finally develop a subsidy mechanism to achieve supply chain coordination and get the feasible range of parameter to lead win-win outcomes under supply disruption situation.
\end{abstract}

\section{Introduction}

Supply disruption means that the supplier's supply capacity cannot meet the requirements of the original order due to various reasons. The phenomenon of supply disruption has always existed. But with the following conditions, probability of disruption increases rapidly.

Firstly, with the increasing of land price and the uncertainty of market demand, inventory holding cost and risk increase rapidly. In order to reduce the cost and risk, many companies began to reduce their inventory level and even adopt just-in-time inventory. The low level of inventory leads probability of disruption to increase. Secondly, globalization business leads to increase the distance between the members of supply chain which greatly increase the uncertainty of logistic. It also increases the probability of disruption. For the supply chain of agricultural product, because agricultural product is perishable, inventory holding cost and risk is more than general product and the uncertainty of logistic also has more impact on agricultural product. Therefore, comparing with the general supply chain, the supply chain of agricultural product has a greater possibility of disruption.

Based above, many researchers begin to study how to deal with the supply disruption. These researches can be divided into two streams. The one stream is to study how to do before the supply disruption. Hendricks and Singhal (2005) first study impact of supply disruption on the enterprise's performance, and propose some suggestions for this issue [1]. Sarkar and Mohapatra (2009) study optimal decision of supplier scale under different supply risk [2]. Pal et al. (2012) study the order 
decision of manufacturer when the supply disruption may happen under multi-echelon supply chain [3]. Hu et al. (2013) develop a combination of overproduction risk sharing and buy-back contracts with a side payment to the backup supplier which can coordinate the supply chain under the risk of supply disruption [4]. Gülpınara et al. (2014) study on how to determine robust investment strategies in petroleum markets under the risk of supply disruption [5]. Habermann et al. (2015) explore two supply chain design strategies to reduce the loss when the supply disruption may happen [6]. The other stream is to study how to deal with the supply disruption when it has happen. Zhu (2013) study a joint decision problem for production, pricing strategies when the supply disruption happens [7]. He et al. (2015) propose an emergency procurement strategy to deal with the supply disruption [8].

This paper belongs to the second stream. However, almost all extant research just investigates retailer's optimal decision. This paper is not only from retailer's perspective, but also study the supplier's optimal replenishment decision. In additional, this paper also develops a subsidy mechanism to achieve the supply chain coordination after the supply disruption happened.

\section{Model description and normal analysis}

Model description. Consider an agricultural supply chain with a supplier (she), a retailer (he) and a spot market. Under the normal situation, the supplier produces a single product at cost $c$ per unit and supplies the retailer at a unit wholesale price $\omega_{1}$. Meanwhile, the supplier provides a quantity discount contract to achieve supply chain coordination. The quantity discount contract means that if the retailer's ordering quantity is more than discount point $t$, the wholesale price will decrease to $(1-\lambda) \omega_{1}, 0<\lambda<1$. The retailer faces a newsvendor problem and his customer demand is $\mathrm{D}$ with a cumulative probability distribution $F(\cdot)$. He purchases $q_{1}$ from the supplier and sells to customers at unit price $\mathrm{p}$. A unit salvage value is $\mathrm{v}$ if the product does not sell at end of sales period. When the supply disruption happens, the supplier's supply capacity $\mathrm{T}$ cannot meet the original ordering quantity. At that moment, the supplier can replenish product $\mathrm{q}_{2}$ from a spot market at a unit price $\omega_{2}, \quad c<\omega_{2}<$ p. We use $\Pi$ and $\Pi^{\text {sd }}$ denote the profit function under normal situation and disruption situation respectively.

Normal analysis. Based on above description, we know that the supply chain achieve coordination by using a quantity discount contract under the normal situation. Lal and Staelin(1984) discuss in detail how to use the quantity discount contract to coordinate supply chain [9]. Based on it, we can get the following optimal decisions: optimal ordering quantity $\mathrm{q}_{1}^{*}=\mathrm{F}^{-1}[(\mathrm{p}-\mathrm{c}) /(\mathrm{p}-\mathrm{v})]$, discount point $t=q_{1}^{*}$, and wholesale price $(1-\lambda) \omega_{1} \cdot q_{1}^{0}$ denotes the optimal ordering quantity in decentralized supply chain under the normal situation.

\section{Replenishment decision under supply disruption}

Centralized supply chain. In the centralized supply chain, the supplier and retailer act like they belong to the same parent-company. So the common goal is to maximize the total profit of the entire supply chain. The centralized supply chain's expected profit under disruption, denoted as $\Pi_{\mathrm{rs}}^{\mathrm{sd}}$, is:

$$
\Pi_{\mathrm{rs}}^{\mathrm{sd}}(\mathrm{Q})=\mathrm{pS}(\mathrm{Q})+\mathrm{v}[\mathrm{Q}-\mathrm{S}(\mathrm{Q})]-\mathrm{cT}-\omega_{2}(\mathrm{Q}-\mathrm{T}) \quad \mathrm{T} \leq \mathrm{Q} \leq \mathrm{q}_{1}^{*}
$$

We then can get the following proposition:

Proposition 1 . In the centralized supply chain, the optimal replenishment quantity under supply disruption is $\mathrm{q}_{2}^{*}=\max \left[\mathrm{Q}^{*}-\mathrm{T}, 0\right]$. 
From Proposition 1, we know that if supply disruption happens, the supplier should replenish $\mathrm{q}_{2}^{*}$ which can maximize profit of supply chain, i.e., use the minimal loss to cope with the disruption. In additional, because $\omega_{2}>c$, we can get optimal supply quantity $Q^{*}$ is less than original ordering quantity $\mathrm{q}_{1}^{*}$.

Decentralized supply chain. In the decentralized supply chain, the supplier will make replenishment decision independently to maximize her own profit. The supplier's expected profit under disruption, denoted as $\Pi_{\mathrm{s}}^{\mathrm{sd}}$, is:

$$
\Pi_{\mathrm{s}}^{\text {sd }}(\mathrm{Q})=\mathrm{Q}(1-\lambda) \omega_{1}-\mathrm{cT}-\omega_{2}(\mathrm{Q}-\mathrm{T}) \quad \mathrm{T} \leq \mathrm{Q} \leq \mathrm{q}_{1}^{*}
$$

We then can get the following proposition:

Proposition 2. In the decentralized supply chain, the supplier's optimal replenishment quantity $\mathrm{q}_{2}^{0}$ under supply disruption is as follow. If $(1-\lambda) \omega_{1} \geq \omega_{2}, \mathrm{q}_{2}^{0}=\mathrm{q}_{1}^{*}-\mathrm{T}$; if $(1-\lambda) \omega_{1}<\omega_{2}$, $\mathrm{q}_{2}^{0}=\mathrm{q}_{1}^{*}-\mathrm{T}$.

From Proposition 2, we know that supplier should decide her replenishment quantity according to the relation between replenishment price and the original wholesale price.

We next study how many supply quantity the retailer hopes the supplier to provide when supply disruption happens. In the normal situation, only if the retailer's ordering quantity is more than discount point $q_{1}^{*}$, he can purchase from supplier at a unit wholesale price $(1-\lambda) \omega_{1}$. However, under supply disruption, the retailer can a get product at a unit wholesale price $(1-\lambda) \omega_{1}$ when supplier's supply quantity is less than $\mathrm{q}_{1}^{*}$. Therefore, The retailer's expected profit under disruption, denoted as $\Pi_{\mathrm{r}}^{\mathrm{sd}}$, is:

$$
\Pi_{\mathrm{r}}^{\mathrm{sd}}(\mathrm{Q})=\mathrm{pS}(\mathrm{Q})+\mathrm{v}[\mathrm{Q}-\mathrm{S}(\mathrm{Q})]-(1-\lambda) \omega_{1} \mathrm{Q} \quad \mathrm{T} \leq \mathrm{Q} \leq \mathrm{q}_{1}^{*}
$$

Taking Eq. (5) the first order condition with respect to $Q$ and makes it equal to 0, we can have:

$$
\Pi_{\mathrm{r}}^{\mathrm{sd}}(\mathrm{Q})^{\prime}=(\mathrm{p}-\mathrm{v}) \mathrm{S}(\mathrm{Q})^{\prime}-\left[(1-\lambda) \omega_{1}-\mathrm{v}\right]=0 \quad \mathrm{~T} \leq \mathrm{Q} \leq \mathrm{q}_{1}^{*}
$$

The solution of Eq. (6) is:

$$
\mathrm{Q}_{\mathrm{r}}^{*}=\mathrm{F}^{-1}\left(\frac{\mathrm{p}-(1-\lambda) \omega_{1}}{\mathrm{p}-\mathrm{v}}\right)
$$

Because $(1-\lambda) \omega_{1}>c$, we can get $Q_{r}^{*}<q_{1}^{*}$. Based on above, we can get the following proposition:

Proposition 3. In the decentralized supply chain, the retailer hopes the supplier to provide $\mathrm{Q}_{\mathrm{r}}^{*}=\mathrm{F}^{-1}\left(\frac{\mathrm{p}-(1-\lambda) \omega_{1}}{\mathrm{p}-\mathrm{v}}\right)$ which is less than original ordering quantity $\mathrm{q}_{1}^{*}$ under supply disruption.

From proposition 2, we know that when supply disruption happens, the retailer does not hope the supplier to provide original ordering quantity for him, while is less than this quantity. It is consistent with centralized supply chain.

\section{Supply chain coordination}

According to Cachon [10], feasible coordinating mechanism should first provide incentives for the members of the decentralized supply chain to make decisions consistent with centralized supply chain, i.e., $\mathrm{q}_{2}^{0}=\mathrm{q}_{2}^{*}$. Second, arbitrary divisions of the supply chain's profit can be implemented by adjusting contractual parameters. We firstly compare $q_{2}^{0}$ and $q_{2}^{*}$. The results in detailed are shown in table 1 . 
Table 1 Supply chain coordination conditions under supply disruption

\begin{tabular}{|c|c|c|c|}
\hline Detailed cases & $q_{2}^{0}$ & $q_{2}^{*}$ & $\begin{array}{l}\text { Coordinatio } \\
\text { n conditions }\end{array}$ \\
\hline$(1-\lambda) \omega_{1} \geq \omega_{2}, \quad Q^{*} \geq \mathrm{T}$ & $q_{1}^{*}-T$ & $Q^{*}-T$ & NO \\
\hline$(1-\lambda) \omega_{1} \geq \omega_{2}, \quad Q^{*}<\mathrm{T}$ & $q_{1}^{*}-T$ & 0 & NO \\
\hline$(1-\lambda) \omega_{1}<\omega_{2}, \quad Q^{*} \geq \mathrm{T}$ & 0 & $Q^{*}-T$ & NO \\
\hline$(1-\lambda) \omega_{1}<\omega_{2}, \quad Q^{*}<\mathrm{T}$ & 0 & 0 & YES \\
\hline
\end{tabular}

From table 1, we find that except for last case, the supply chain does not achieve coordination under other cases. Therefore, we will develop a mechanism which can derive the supplier to set replenishment quantity equal to $\mathrm{q}_{2}^{*}$ and lead to win-win outcomes. We first discuss the first case, i.e., $\quad(1-\lambda) \omega_{1} \geq \omega_{2}, \quad Q^{*} \geq T$.

Under the first case, the supplier' optimal replenishment quantity $q_{2}^{0}$ is more than $q_{2}^{*}$. If we want supplier to reduce her replenishment quantity, we need to make her profits under $\mathrm{q}_{2}^{*}$ is more than that under $\mathrm{q}_{2}^{0}$. Therefore, we need to establish a profits transfer mechanism which can transfer a part of increased profits of retailer to the supplier. This paper will propose a subsidy mechanism to achieve it. This mechanism means that if the supplier' supply quantity $Q\left(Q=q_{2}^{0}+T\right)$ is less than $Q^{*}$ under supply disruption, the retailer provide $\alpha \omega_{1}(\alpha>0)$ subsidy per unit for supplier. Under this mechanism, the supplier and retailer's expected profit, denoted as $\Pi_{\mathrm{s}}^{\mathrm{sd}}$ and $\Pi_{\mathrm{r}}^{\mathrm{sd}}$, are:

Supplier's expected profit:

$$
\Pi_{s}^{s d}(Q)=\left\{\begin{aligned}
Q(1-\lambda+\alpha) \omega_{1}-c T-\omega_{2}(\mathrm{Q}-\mathrm{T}) & \mathrm{T} \leq \mathrm{Q} \leq Q^{*} \\
Q(1-\lambda) \omega_{1}-c T-\omega_{2}(\mathrm{Q}-\mathrm{T}) & \mathrm{Q}>Q^{*}
\end{aligned}\right.
$$

Retailer's expected profit:

$$
\Pi_{r}^{s d}(Q)=\left\{\begin{array}{rl}
p S(Q)+v[Q-S(Q)]-(1-\lambda+\alpha) \omega_{1} \mathrm{Q} & \mathrm{T} \leq \mathrm{Q} \leq Q^{*} \\
p S(Q)+v[Q-S(Q)]-(1-\lambda) \omega_{1} \mathrm{Q} & \mathrm{Q}>Q^{*}
\end{array}\right.
$$

Based on Proposition 1-2, we know that when the supply quantity $Q$ deceases from $q_{1}^{*}$ to $Q^{*}$, the profits of supply chain increases. So the retailer's increased profits is more than supplier's decreased profits when $\mathrm{Q}$ deceases from $\mathrm{q}_{1}^{*}$ to $\mathrm{Q}^{*}$. Therefore, we can find the suitable range of $\alpha$ to lead the retailer and supplier to achieve win-win outcomes. To achieve win-win outcomes, $\alpha$ must satisfy the following inequality:

$$
\left\{\begin{array}{c}
Q^{*}(1-\lambda+\alpha) \omega_{1}-\omega_{2}\left(Q^{*}-T\right) \geq q_{1}^{*}(1-\lambda) \omega_{1}-\omega_{2}\left(q_{1}^{*}-T\right) \\
p S\left(Q^{*}\right)+v\left[Q^{*}-S\left(Q^{*}\right)\right]-(1-\lambda+\alpha) \omega_{1} Q^{*} \geq p S\left(q_{1}^{*}\right)+v\left[q_{1}^{*}-S\left(q_{1}^{*}\right)\right]-(1-\lambda) \omega_{1} q_{1}^{*}
\end{array}\right.
$$

The solution of Ineq. (9) is:

$$
\alpha \in\left[\frac{\left(q_{1}^{*}-Q^{*}\right)\left[(1-\lambda) \omega_{1}-\omega_{2}\right]}{\omega_{1} Q^{*}}, \frac{(p-v)\left[S\left(Q^{*}\right)-S\left(q_{1}^{*}\right)\right]+\left(q_{1}^{*}-Q^{*}\right)\left[(1-\lambda) \omega_{1}-v\right]}{\omega_{1} Q^{*}}\right]
$$

From above, we can get the following proposition:

Proposition 4 . When $(1-\lambda) \omega_{1} \geq \omega_{2}$ and $Q^{*} \geq T$, if the supplier's supply quantity $Q$ is less than $Q^{*}$ under supply disruption, the retailer provide $\alpha \omega_{1}$ subsidy per unit for supplier which can lead supply chain to coordinate. Where $\alpha \in\left[\frac{\left(q_{1}^{*}-Q^{*}\right)\left[(1-\lambda) \omega_{1}-\omega_{2}\right]}{\omega_{1} Q^{*}}, \frac{(p-v)\left[S\left(Q^{*}\right)-S\left(q_{1}^{*}\right)\right]+\left(q_{1}^{*}-Q^{*}\right)\left[(1-\lambda) \omega_{1}-v\right]}{\omega_{1} Q^{*}}\right]$.

We adopt the same method to study the other two cases. And then we can get the following propositions

Proposition 5. When $(1-\lambda) \omega_{1} \geq \omega_{2}$ and $Q^{*}<T$, if the supplier's supply quantity $Q$ is less than $\mathrm{T}$ under supply disruption, the retailer provide $\alpha \omega_{1}$ subsidy per unit for supplier which can lead supply chain to coordinate. Where $\alpha \in\left[\frac{\left(q_{1}^{*}-T\right)\left[(1-\lambda) \omega_{1}-\omega_{2}\right]}{\omega_{1} T}, \frac{(p-v)\left[S(T)-S\left(q_{1}^{*}\right)\right]+\left(q_{1}^{*}-T\right)\left[(1-\lambda) \omega_{1}-v\right]}{\omega_{1} T}\right]$. 
Proposition 6. When $(1-\lambda) \omega_{1}<\omega_{2}$ and $Q^{*} \geq T$, if the supplier's supply quantity $\mathrm{Q}$ is more than $Q^{*}$ under supply disruption, the retailer provide $\alpha \omega_{1}$ subsidy per unit for supplier which can lead supply chain to coordinate. Where $\alpha \in\left[\frac{\left(T-Q^{*}\right)\left[(1-\lambda) \omega_{1}-\omega_{2}\right]}{\omega_{1} Q^{*}}, \frac{(p-v)\left[S\left(Q^{*}\right)-S(T)\right]+\left(T-Q^{*}\right)\left[(1-\lambda) \omega_{1}-v\right]}{\omega_{1} Q^{*}}\right]$.

Propositions 4-6 imply that when the retailer provide subsidy for supplier under supply disruption, he should pay more attention on the actual situation, such as, replenishment price and the rest of supply capacity.

\section{Conclusions and further research}

This paper gets the optimal replenishment decision in the centralized and decentralized supply chain under supply disruption. By comparing these results between the centralized and decentralized supply chain, we find that the replenishment decision under decentralized supply chain is not consistent with that under centralized supply chain in most cases. To solve this issue, we develop a subsidy mechanism and obtain the feasible range of parameter to achieve win-win outcomes.

We also find a useful managerial insight. When the supply disruption happens, the supplier does not immediately make the replenishment decision just according to her own situation. Meanwhile, the retailers also does not force supplier to meet original ordering quantity. They should work together to make replenishment decision on the basis of replenishment price and the rest of supply capacity, which can effectively reduce the loss caused by the supply disruption.

Two possible extensions of this work can be adopted. Firstly, instead of just considering the supply disruption, we next will consider supply disruption and demand disruption simultaneously. Secondly, instead of just considering single retailer and single supplier, we next will extend the model to multiple retailers or suppliers.

\section{Acknowledgments}

This work is supported by the Research and Innovation Program of Postgraduates in Jiangsu Province (No. KYLX_1351).

\section{References}

[1] K. B. Hendricks and V. R. Singhal, An empirical analysis of the effect of supply chain disruptions on long-run stock price performance and equity risk of the firm, Production and Operations management, vol.14, no.1, pp. 35-52, 2005.

[2] A. Sarkar and P. K. J. Mohapatra, Determining the optimal size of supply base with the consideration of risks of supply disruptions, International Journal of Production Economics, vol.119, no.1, pp. 122-135, 2009.

[3] B. Pala, S. S. Sanab and K. Chaudhuria, A multi-echelon supply chain model for reworkable items in multiple-markets with supply disruption, Economic Modelling, vol.29, no.5, pp. 1891-1898, 2012.

[4] F. Hu, C. C. Lim, Z.D. Lu and X. C. Sun, Coordination in a Single-Retailer Two-Supplier Supply Chain under Random Demand and Random Supply with Disruption, Discrete Dynamics in Nature and Society ,vol. 2013, pp. 1-12, 2013. 
[5] N. Gülpınara, E. Canakoglub and D. Pachamanovac, Robust investment decisions under supply disruption in petroleum markets, Computers \& Operations Research, vol. 44, pp. 75-91, 2014.

[6] M. Habermann, J. Blackhurst and A. Y. Metcalf, Keep Your Friends Close? Supply Chain Design and Disruption Risk, Decision Sciences, 2015

[7] S. X. Zhu, Dynamic replenishment, production, and pricing decisions, in the face of supply disruption and random price-sensitive demand, International Journal of Production Economics, vol.146, no.2, pp. 612-619, 2013.

[8] B. He, H. Huang and K. F. Yuan, The comparison of two procurement strategies in the presence of supply disruption, Computers \& Industrial Engineering, vol. 85, pp. 296-305, 2015.

[9] R. Lal and R. Staelin, An approach for developing an optimal discount pricing Policy, Management Science, vol.30, no.12, pp. 1524-1539, 1984.

[10] G. P. Cachon, Supply chain coordination with contracts, Handbooks in operations research and management science, vol. 11, pp. 227-339, 2003. 